\title{
El vicio de leer
}

\section{$M^{a}$ DEL MAR BONET}

Cantautora

Mi padre fue el culpable, si se puede decir así, de mi primer contacto con los libros. Escritor y periodista, él fomentaba en nosotros de una manera natural y cotidiana, con su ejemplo, la necesidad de la lectura. Poco a poco, creciendo a su lado, convivíamos con ese vicio incurable y crónico.

Los primeros recuerdos del contacto con los libros también vienen de la escuela primaria y, sobretodo, de mi abuelo Ramón. Él llenaba el vacío de nuestra lengua materna, el catalán que en la escuela estaba prohibido. El abuelo tenía libros de la República, traducciones al catalán de Julio Verne, cuentos..., con ellos nos enseñaba a leer y a escribir. Lo recuerdo con su paciencia infinita en la mesa del comedor, cada día un rato después del colegio. Lo hacían venir para ayudarme a repasar las matemáticas, que no me interesaban pero a las que él sabía darles un interés especial que no encontré nunca más en ningún profesor.

En aquellos primeros años de lecturas y aprendizajes en casa, yo libraba una pequeña guerra con mi abuela Dolores. Era una persona muy cariñosa, y se hacía querer. De ella aprendí muchas canciones y cuentos. Nunca se cansaba de nuestras peticiones, pero era un poco machista, y en los trabajos de la casa en los que colaborábamos los niños, la que se llevaba el premio de la limpieza era yo, y no mi hermano. Mi madre intentaba luchar contra esta tendencia, pero la abuela tenía algunas convicciones muy enraizadas. Por ejemplo, para ella el hecho de encontrarme leyendo en algún rincón de la casa era un vicio que se afanaba en corregir. Inmediatamente me 
reclamaba para que la ayudara en cualquier cosa, o me mandaba hacer algún recado. Yo me despedía a regañadientes de aquel momento dulce de la lectura, pues sabía que la abuela no me dejaría volver a él hasta que ella se distrajera o le viniera el sueño en su balancín. Entonces, sigilosamente, podría volver al punto donde había abandonado el libro. Si yo estaba enferma la yaya claudicaba. Aquello era la gloria: los libros de cuentos, y 'rondalles' de Mallorca, Julio Verne, Guillermo Brown... me llenaban la cama y las horas y me hacían olvidar aquella fiebre. El poder de la abuela menguaba mucho si mi madre estaba en casa. Yo leía a mis anchas y ella no podía hacer nada. Si tenía el libro abierto y ella pasaba cerca de mi yo la miraba de reojo, me sabía de memoria su gesto de desaprobación.

En casa había un sitio sagrado donde la yaya entraba muy poco. Era el despacho de mi padre. En aquella cierta soledad podía encontrar todo tipo de lecturas. Sabía el estante donde me esperaba Tirant lo Blanc y montañas de revistas: 'La codorniz', 'Correo de la Unesco', 'Destino' y tantas novelas y libros de arte. Todos me esperaban, lejos de la mirada de la abuela.

Mi padre, en el diario 'Baleares', se ocupaba también de la crítica literaria. Por aquél entonces llegaban a casa paquetes de libros procedentes de Barcelona y Madrid. Mi hermano y yo teníamos permiso para abrirlos. Llegaban colecciones enteras de 'Adonais', 'Austral', 'Áncora y Delfín'... teníamos el privilegio de sentir el perfume de los libros nuevos, sin abrir.

Después del cole, alguna vez coincidíamos con mi padre en un paseo por la ciudad. Invariablemente teníamos algunas paradas obligatorias: una era la librería Ereso, que él frecuentaba mucho. Allí estaba su amigo Tomeu Payeras, que nos dejaba, para estar a solas con mi padre, dar vueltas por la librería y husmearlo todo. También entrábamos a 'Libros Mallorca', muy cerca de nuestra casa, donde encontré mi primer ejemplar de los poemas de Bartomeu Rosselló Pòrcel. Y más adelante una pequeñísima librería llamada 'El cavall verd', milagrosa para mí porque únicamente vendía poesía y la regentaba un inolvidable poeta, Rafael Jaume. 
Entrar en una librería que te gusta, en la que a veces conoces a los libreros, se convierte en un ritual que contiene una dosis elevada de felicidad. Recorrer los mostradores y estantes, escoger y dejar para el final el placer de lo que te gusta más: los estantes y mesas de poesía. Una ojeada pausada y finalmente recoger como si fuera en una huerta todos los frutos que te interesan, pensando en el placer que te darán después.

A los 18 años llegué a Barcelona para estudiar cerámica en la Escola Massana, y con el tiempo empecé a trabajar en una fábrica de cerámica de Horta. Alquilé una habitación de una casita muy cercana a mi trabajo. Consideré este lugar como mi primera casa independiente, ya lejos del nido familiar. Un día, cuando hacía pocos meses que vivía allí, me llegó un paquete grande procedente de Mallorca. Lo mandaba mi padre. Lo abrí despacito, emocionada: me enviaba una selección de libros en los que había un poco de todo: El Quijote, Larra, Quevedo, Valle-Inclán, Unamuno, Oscar Wilde, William Shakespeare... También el Quadern gris de Joseph Pla, Bearn de Villalonga, una antología de poesía catalana; aquel Tirant lo Blanc que yo leía en su despacho, un librito de poemas de mi amigo Damià Huguet, que yo había dejado en mi habitación cuando me marché. Fue mi primera biblioteca, todavía la conservo.

En casa reservo un sitio para la lectura, siempre el mismo. No puedo oír música, tiene que ser en silencio. Me gusta crear una cierta clandestinidad, como cuando me escondía de la abuela.

Una buena luz, una butaca cómoda con una mesa baja al lado y algunos libros, de poesía si puede ser... y saber que tengo un par de horas para dedicarlas a la lectura, sin prisas.

(Artículo recibido: 01-12-2010; aceptado: 10-12-2010) 